\title{
EL SANTANDER DE PEREDA: SOTILEZA (1885) Y NUBES DE ESTÍO (1891)
}

\author{
José Manuel GONZÁLEZ HERRÁN \\ Universidade de Santiago de Compostela
}

\section{RESUMEN}

Aunque suele decirse que Sotileza (1885) es la más santanderina de las novelas de José María de Pereda, acaso lo sea aún más Nubes de estío (1891). Este trabajo se propone analizar cómo en cada una de ambas novelas el mismo ambiente urbano -la ciudad de Santander- se manifiesta de manera muy distinta. Ante todo, por los cincuenta años que separan el tiempo histórico de cada una de ellas; pero también porque cada una de ambas novelas se han escrito con intenciones y objetivos diferentes, aunque desde idénticos presupuestos estéticos y morales.

Palabras clave: José María de Pereda, novela, historia, ciudad, Santander, Sotileza, Nubes de estío.

\section{ABSTRACT}

It is usually believed that Sotiliza (1885) by Jose Maria de Pereda is the novel where the author more accurately depicts the city of Santander; however it might be Nubes de estío (1891) where Santander is even better represented. This work explores how in both novels the same urban atmosphere, the city of Santander, is represented in diverse ways.

The main reason is the time lapse of fifty years between both novels. Also, because even though both novels share the same moral and esthetic premises, they were written with very different objectives and intentions.

Key words: José María de Pereda, novel, history, city, Santander, Sotileza, Nubes de estío. 
Suele decirse que Sotileza es la más santanderina de las novelas de su autor: en mi opinión esta que ahora presento es la que con más justicia merece esa credencial; cuando Pereda refleja en aquélla la vida de las gentes pescadoras, es evidente que no habla de los suyos (y acaso por ello es más meritoria su destreza en conseguirlo), mientras que sí advertimos un más verosímil realismo en los pasajes ambientados en los interiores burgueses de los marinos de entonces, en los escritorios del Muelle, en los palcos del teatro o en los callejeos por la ciudad... Otro tanto sucede en Nubes de estío, donde el autor se encentra tan en su ambiente que (como algunos pintores de la burguesía flamenca) no resiste la tentación de incluirse a sí mismo en el cuadro. Precisamente esa presencia autorial tiene que ver con otra notable diferencia entre ambas novelas santanderinas: si la de 1885 pretendía ser una evocación -teñida de la nostalgia ante las cosas ya desaparecidas- de la ciudad en los años infantiles de Pereda, la de 1891 refleja un Santander rigurosamente coetáneo, que los primeros lectores pudieron fácilmente identificar y reconocer. (González Herrán, 1999: 434).

Permítaseme que, para plantear la cuestión que aquí pretendo estudiar, haya recordado un antiguo texto mío, cuyo asunto -las semejanzas y diferencias entre esos dos títulos ${ }^{1}$ he reiterado en otra ocasión (González Herrán, 2006). En esta me propongo analizar cómo en cada una de ambas novelas el mismo ambiente urbano -la ciudad de Santander- se manifiesta de manera muy distinta; y no solo porque hayan pasado unos cincuenta años, sino -sobre todoporque las dos novelas se han escrito con intenciones y objetivos diferentes, aunque desde idénticos presupuestos estéticos y morales.

En efecto, en la primera de aquellas novelas, su autor recrea de manera admirable y poética (a propósito escribo en cursiva esa palabra) el Santander marinero y pescador en el que transcurrieron algunos años de su infancia y primera juventud, más o menos entre 1842 y $1856^{2}$; pero conviene recordar que aquel muchacho no era un marinero ni un pescador, sino un señorito, que, como mucho, jugaba a ser «raquero» ${ }^{3}$ : algo muy parecido a lo que hace

1. Que no he sido el primero en advertir: «un libro [Nubes de estío] nada semejante a Sotileza, porque los tipos serán los del otro Santander, el de los burgueses y comerciantes, el del mundillo literario que le rodea; un mundo aparte, sin conexión con el de marineros y pescadores reflejado en su primera novela de la capital» (Gullón, 1944: 206-207).

2. En su edición de Sotileza, Simón Cabarga ofrece algunos datos que permiten fijar la cronología del relato: así, cuando en el capítulo III Andrés se dirige a la calle de la Mar «atravesando una galería de los Mercados de la Plaza Nueva», ello «nos sitúa justo en el año 1842, reciente la inauguración de tal mercado, que fue acontecimiento local» (Pereda, 1977: 92); más adelante, ya en el capítulo XII, anota: «ahora Silda [la protagonista] tenía ya veinte años. Estamos en los alrededores del año 1856» (Pereda, 1977: 192).

3. Así lo definía Pereda en «Significación de algunas voces técnicas y locales usadas en este libro, para inteligencia de los lectores profanos», vocabulario que añadió al final de Sotileza, y que suele reproducirse en todas las ediciones: «Raquero, loc.- Muchacho que 
el personaje Andrés en la novela. Las gentes, los trabajos, las diversiones, las casas y las calles que se evocan con arte admirable en las páginas de Sotileza pertenecen a un mundo ajeno al autor, aunque le sea entrañablemente querido; un mundo evocado en la distancia temporal, con ese tinte embellecedor que proporciona la nostalgia.

Nostalgia que no excluye -más bien, la exige- una actitud crítica respecto a los cambios que han traído los nuevos tiempos, y que se expone de manera harto explícita en el Prólogo-Dedicatoria, «A mis contemporáneos de Santander que aún vivan». Darío Villanueva ha dedicado páginas muy sagaces (Villanueva, 2004: 130-133) a explicar el sentido de ese texto, donde Pereda declara palmariamente haber escrito su relato con la intención de que esos «contemporáneos» puedan reconocerse en tal escenario, tan cambiado en los últimos años. "Al fin y a la postre lo que en él [el libro] acontece no es más que un pretexto para resucitar gentes, cosas y lugares que apenas existen ya, y reconstruir un pueblo, sepultado de la noche a la mañana, durante su patriarcal reposo, bajo la balumba de otras ideas y otras costumbres arrastradas hasta aquí por el torrente de una nueva y extraña civilización» (Pereda, 1996: 65).

Esa nueva ciudad, que ha sepultado al viejo pueblo dormido en «su patriarcal reposo», es precisamente la que aparecerá en Nubes de estío, cuyas páginas recrean el Santander de casi cincuenta años después, en los días en que la novela se escribe y publica. Cuando Laureano Bonet se refiere al Santander de Sotileza como «aún no adulterado por el tráfago industrial y la vida grisácea de la burguesía» (Bonet, 1980: 17), parece estar apuntando al ambiente de la novela de 1891: un tráfago más comercial que industrial es lo que ocupa a la burguesía grisácea de Nubes de estío, cuyo escenario urbano es el Santander convertido en capital del veraneo, cuyos «encantos» el mismo Pereda había puesto en duda y ridiculizado con las caricaturas de su libro Tipos trashumantes $(1877)^{4}$.

También Sotileza tenía precedentes en la narrativa breve del autor: ya algunos de sus primeros relatos costumbristas (principalmente «La leva», de

se dedica al merodeo entre los buques de la dársena, a la bajamar, en muelles, careneros, etc.» (Pereda, 1996: 409).

4. Ya notó Montesinos, 1969: 229 la coincidente «especie de moraleja antiveraniega»; por mi parte, he explicado así su dimensión costumbrista: «Una misma visión caricaturesca del veraneo -que ahora une en su sátira a los visitantes madrileños con los visitados de la capital provinciana- hace que, además de en asunto, ambiente y tipología humana, ambos libros coincidan en la manera costumbrista con que está vista y mostrada buena parte de esa sociedad» (González Herrán, 1998: 447). 
Escenas Montañesas, aludido en la página final de Sotileza $a^{5}$ ) recreaban los ambientes que había tenido ocasión de conocer -aunque de lejos- durante los años de su infancia y adolescencia santanderina. El citado Bonet lo ha explicado de manera ajustada y convincente: «[Pereda] descubrirá con sus compañeros de juego el viejo Santander de la Maruca y el Muelle-Anaos, el vistoso mundo de los mareantes ya las callealteras, la miseria y el hollín, el olor a brea y a parocha: atmósfera que nutrirá como 'materia' nostálgica diversos relatos de Escenas montañesas y Tipos y paisajes y, sobre todo, establecerá la escenografía bulliciosa y hambrienta, agria e irónica de Sotileza»; y añade luego un comentario muy sugestivo ( «Un Santander mitificado por el recuerdo, inmóvil en la lejanía -no olvidemos que la inmovilidad es uno de los rasgos fundamentales del relato costumbrista-»; Bonet, 1980: 15-17), pues nos ayudará a entender el tratamiento del escenario urbano en las dos novelas que me ocupan. Como creo haber demostrado en otra ocasión (González Herrán, 1998), la narrativa perediana está muy determinada por el peso -o el lastredel costumbrismo, y a ello no son ajenas estas dos novelas.

El capítulo I de Sotileza tiene la apariencia de una escena teatral: tres párrafos descriptivos, a modo de acotaciones ${ }^{6}$ y un extenso diálogo que transcribe la lección de un clérigo exclaustrado al grupo de chiquillos de la calle a quienes intenta adoctrinar. Una línea de puntos separa ese cuadro del párrafo que cierra el capítulo, y que constituye toda una declaración, inequívocamente autorial, que conviene citar íntegramente:

Todo esto acontecía en una hermosa mañana del mes de junio, bastantes años... muchos años hace, en una casa de la calle de la Mar, de Santander; de aquel Santander sin escolleras ni ensanches; sin ferrocarriles ni tranvías urbanos; sin la plaza de Velarde y sin vidrieras en los claustros de la catedral; sin hoteles en el Sardinero y sin ferias ni barracones en la Alameda segunda;

5. «De lo que ocurrió en la punta del Muelle con ocasión de embarcarse los mareantes de la leva para el servicio de la patria, debo decir yo aquí muy poco, después de haber consagrado en otra parte [Escenas Montañesas, nota del autor] largas páginas a ese duro tributo impuesto por la ley de entonces al gremio de pescadores» (Pereda, 1996: 400).

6. Cito solo el primero: «El cuarto era angosto, bajo de techo y triste de luz; negreaban a partes las paredes, que habían sido blancas, y un espeso tapiz de roña, empedernida casi, cubría las carcomidas tablas del suelo. Contenía una mesa de pino, un derrengado sillón de vaqueta y tres sillas desvencijadas; un crucifijo con un ramo de laurel seco, dos estampas de la Pasión y un rosario de Jerusalén, en las paredes; un tintero de cuerno con pluma de ave, un viejo breviario muy recosido, una carpetilla de badana negra, un calendario y una palmatoria de hoja de lata, encima de la mesa; y, por último, un paraguas de mahón azul con corva empuñadura de asta, en uno de los rincones más oscuros. El cuarto tenía también una alcoba, en cuyo fondo, y por los resquicios que dejaba abiertos una cortinilla de indiana, que no alcanzaba a tapar la menguada puerta, se entreveía una pobre cama, y sobre ella un manteo y un sombrero de teja» (Pereda, 1996: 71-72). 
en el Santander con dársena y con pataches hasta la Pescadería; el Santander del Muelle-Anaos y de la Maruca; el de la Fuente Santa y de la Cueva del tío Cirilo; el de la Huerta de los Frailes en abertal, y del provincial de Burgos envejeciéndose en el cuartel de San Francisco; el de la casa de Botín, inaccesible, sola y deshabitada; el de los Mártires en la Puntida, y de la calle de Tumbatrés; el de las gigantillas el día 3 de noviembre, aniversario de la batalla de Vargas, con luminarias y fuegos artificiales por la noche, y de las corridas en que mataba Chabiri, picaba el Zapaterillo, banderilleaba Rechina, y capeaba el Pitorro, en la plaza de Botín, con música de los Nacionales; el Santander de los Mesones de Santa Clara, del Peso Público y de Mingo, la Zulema y Tumbanavios; del Chacolí de la Atalaya y del cuartel del Reganche en la calle de Burgos; del parador de Hormaeche, y de la casa del Navio; el Santander de aquellos muchachos decentes, pero muy mal vestidos que, con bozo en la cara todavía, jugaban al bote en la plaza Vieja, y hoy comienzan a humillar la cabeza al peso de las canas, obra, tanto como de los años, de la nostalgia de las cosas venerandas que se fueron para nunca más volver ${ }^{7}$; del Santander que yo tengo acá dentro, muy adentro, en lo más hondo de mi corazón, y esculpido en la memoria de tal suerte, que a ojos cerrados me atrevería a trazarle con todo su perímetro, y sus calles, y el color de sus piedras, y el número, y los nombres, y hasta las caras de sus habitantes; de aquel Santander, en fin, que a la vez que motivo de espanto y mofa para la desperdigada y versátil juventud de ogaño, que le conoce de oídas, es el único refugio que le queda al arte cuando con sus recursos se pretende ofrecer a la consideración de otras generaciones algo de lo que hay de pintoresco, sin dejar de ser castizo, en esta raza pejina que va desvaneciéndose entre la abigarrada e insulsa confusión de las modernas costumbres (Pereda, 1996: 83-84).

Esa detallada enumeración de lugares santanderinos, y de las actividades que allí se desarrollaban, reitera lo apuntado en el prólogo: la ciudad que la novela pretende recrear es la anterior a los cambios producidos en los últimos cuarenta años, que sólo quienes en ella vivieron y aún la recuerdan podrán reconocer. Por esa misma razón se mencionan por sus nombres algunos de sus lugares más característicos (muchos de los cuales todavía hoy se denominan así $)^{8}$.

7. Es evidente que, por boca del narrador, el autor habla de sí mismo, que de muchacho jugó al bote en la plaza Vieja y hoy siente la nostalgia de las cosas «que se fueron para nunca más volver»; y que, como dice líneas más adelante -y demostrará en esta novelase siente capaz de dibujar a ciegas el perímetro de la ciudad, sus calles, sus piedras...

8. Cosa muy diferente de lo que sucede, por ejemplo, en La Tribuna o en La Regenta, cuyos escenarios urbanos llevan nombres ficticios, pero sus referentes pueden ser fácilmente identificables, como bien explicaron Varela Jácome, para La Tribuna (cfr. Pardo Bazán, 1975: 41-44 de la «Introducción», y muchas de las notas) y Martínez Cachero, para La Regenta (cfr. Alas, 1994: xliv-xlix, y el curioso plano que lo complementa). Y ficticios son también en ambas novelas los nombres de las respectivas ciudades: Marineda y Vetusta (lo comento y explico en González Herrán, 2011: 161). 
Ello resulta especialmente notorio en ciertos episodios que podríamos calificar de itinerantes: el narrador acompaña a los personajes en su recorrido por la ciudad, lo que le permite describir, evocar y recrear los lugares del trayecto. Así sucede en el capítulo II, «De la Maruca a San Martín», en cuyo itinerario se van mencionando o mostrando los lugares más característicos (la Maruca, la trasera del Muelle, la calzada de Cañadío, la plaza del Cuadro, la Fuente Santa, la cueva del tío Cirilo, el callejón de la Fábrica de Sardinas, los prados de Molnedo, el Muelluco, los prados y el castillo de San Martín'), matizados a veces con comentarios alusivos al paso del tiempo: «la playa de la parte opuesta, cerrada por la fachada de un almacén que aún existe (...) espacio ocupado hoy por la casa de los Jardines y la plaza del Cuadro, con cuantos edificios y calles le siguen por el norte» (Pereda, 1996: 85); o acompañados de informaciones y recuerdos inequívocamente autoriales (puesto que se declaran como autobiográficos):

¿Quién de los que entonces tuvieran ya uso de razón y vivan hoy, habrá olvidado aquella tarde inverniza y borrascosa en que, apenas avistada al puerto una fragata, se oyó de pronto el tañido retumbante, acompasado, lento y fúnebre del campanón de los Mártires?

[...]

Yo me hallaba en la escuela de Rojí al sonar el campanón, y ninguno preguntó allí: «¿qué fragata es esa?», cuando se nos dijo: «¡la Unión se va a las Quebrantas!» Todos la conocíamos, y casi todos la esperábamos. Con decir que en seguida se nos dio suelta, pondero cuanto puede ponderarse la impresión causada en el público por el suceso [...] No cabe en libros lo que se habló en Santander de aquel triste suceso, que hoy no llevaría dos docenas de curiosos al polvorín de la Magdalena. Y aún fue, pasados los años, tema compasible de muchas y muy frecuentes conversaciones; y, todavía hoy, como se ve por la muestra, sale a colación de vez en cuando (Pereda, 1996: 92-93) ${ }^{10}$.

Sin ser tan minuciosas y detalladas, también importan otras descripciones y evocaciones: del barrio marinero, la Calle Alta, en el capítulo III ${ }^{11}$, y su Paredón, en el VI (que «existe todavía con el mismo nombre, entre la primera casa de la acera del Sur de esta calle y la última de la misma acera de RúaMayor $\left.{ }^{12}\right)$; los escritorios u oficinas de armadores y consignatarios, en el ca-

9. Las abundantes y prolijas notas con que José Simón Cabarga enriqueció su edición de esta novela, demuestran de manera indiscutible la exactitud del novelista en esa ambientación urbana; para lo que se refiere a este capítulo, véase Pereda, 1977: 44-46.

10. También Simón Cabarga precisa los datos de ese episodio evocado por el narrador, en Pereda, 1977: 47-48.

11. Véase la extensa nota de Simón Cabarga en Pereda, 1977: 61-62

12. Y sigue: «Solamente faltan el pretil que amparaba la plazoleta por el lado del precipicio y la ancha escalera de piedra que descendía por la izquierda hasta bajamar, atracadero 
pítulo VIII ${ }^{13}$; los lugares de reunión de los burgueses (el Círculo de Recreo) y los pescadores (la taberna La Zanguina), en el capítulo XIII ${ }^{14}$. Como ya hemos visto, no faltan a veces las reflexiones a propósito de cómo han cambiado las cosas desde entonces; así también, al mencionar en el capítulo VII el Dueso, entonces un fondeadero «salpicado de lanchas y barquías del Cabildo», añade que el «axioma tradicional de 'por mucho que apañes no fundarás en el Dueso', había de ser desacreditado por el genio emprendedor de las siguientes generaciones, plantando en el Dueso mismo la estación del ferrocarril, emblema del espíritu revolucionario y transformador de las modernas sociedades» (Pereda, 1996: 145); o, en el capítulo XXII, alude así a las playas que aún no se habían puesto de moda (y que, como enseguida veremos, serán escenario de Nubes de estío):

El Sardinero, en cuyas soledades se alzó en breves días un edificio, uno solo, destinado a fonda y hospedería, había vuelto a quedarse desierto y abandonado de todos, por obra de un lamentable suceso ocurrido en sus playas. Pasaban veranos, y solamente algún entoldado carro del país, que servía de vehículo y de tienda de campaña a tal o cual necesitado de los tónicos vapuleos de las olas, se veía por allí de tarde en cuando; los bailes campestres, tan afamados después acá, andaban a la sazón a salto de romería, y ni siquiera cuajaban en todas ellas; comenzaba a no ser de mal tono entre las familias pudientes lo que en las mismas ha llegado a vicio de veranear en la aldea; un viaje a Madrid era empresa de tres días, y se contaban por los dedos los santanderinos que conocían de vista la capital de Francia; nos visitaban durante media semana los distinguidos herpéticos de Ontaneda, o lo menos vulgar entre los reumáticos de las Caldas o de Viesgo, al fin de sus temporadas, amén de unas cuantas familias «del interior» que por inexcusable necesidad venían a remojar sus lamparones en las playas de San Martín; y por lo tocante a la gente menuda, que no tenía vapores al Astillero, ni trenes a Boo, ni tranvías urbanos, ni sociedades de baile por lo fino, ni otras recreaciones que tanto abundan ahora; ni estaban absorbidos los pensamientos de los unos por los arduos problemas sociales, ni se desvelaban las otras con los cuidados de remedar en usos y atavío a las señoras de copete, merendaba en el Verdoso o en Pronillo, o triscaba tan guapamente en el Reganche o en los prados de San Roque, con variantes de paseo en los Mercados del Muelle, cuando el tiempo no permitía lucir al aire libre los trapillos domingueros. (Pereda, 1996: 311-312).

de las embarcaciones de aquellos mareantes, hoy parte de un populoso barrio, con la estación del ferrocarril en el centro» (Pereda, 1996: 136); véanse las notas de Simón Cabarga en Pereda, 1977: 105-107.

13. Véanse las notas de Simón Cabarga en Pereda, 1977: 140-141.

14. Véanse las notas de Simón Cabarga en Pereda, 1977: 207-210.

Anales, 24, 2012, pp. 111-124 
Y es que no solo han cambiado los lugares de la ciudad, sino -sobre todo-su perfil social, sus usos y costumbres: así lo comenta el narrador, expresando las opiniones de Andrés (personaje en el que, según coincidente dictamen crítico, el autor puso mucho de sí mismo):

¡Pensar que él gastaba sus ahorros en atavíos de sociedad y de paseo!... Si le fueron insufribles estos lugares cuando había clases y categorías, ¿qué habían de parecerle cuando, desde la introducción de los vapores y de la legión de ingleses traída por Mould a Santander para acometer las obras del ferrocarril, ya podía un mozuelo imberbe salir a la plaza con sombrero de copa alta sin temor de que se le derribaran de la cabeza a tronchazos; andaban por la calle, vestidos de señores, los marinos de la Berrona, sin la menor señal externa de lo que habían sido todos ellos cinco años antes, y Ligo, y Sama, y Madruga, y otros tales, si bien marinos todavía por dentro, y violentándose mucho para no descubrir la hilaza al hablar, mientras andaban por acá iban al Suizo a tomar sorbete, después de haber paseado en la Alameda con levita ceñida y sombrero de copa; y chapurreaban el inglés los chicos de la calle para jugar a las canicas con los rubicundos rapaces de «la soberbia Albión»; y habían caído los paradores de Becedo, y estaba denunciada la casa de Isidro Cortés, entre las dos Alamedas ${ }^{15}$, y en capilla, para ser terraplenada, la dársena chica, y a medio rellenar la Maruca...; y, en fin, que toda carne había corrompido ya su camino, y estaba la población, de punta a cabo, hecha una indignidad de mescolanzas descoloridas y de confusiones intraducibles! (Pereda, 1996: 233-234).

Ese nuevo ambiente urbano y social, visto de manera tan desfavorable («estaba la población, de punto a cabo, hecha una indignidad de mescolanzas descoloridas y de confusiones intraducibles») será el escenario de Nubes de estío.

$\mathrm{Su}$ acción comienza (tras un capítulo inicial en el que la transcripción de una carta nos pone en antecedentes del asunto) precisamente en aquel café donde algunos marinos tomaban sorbete: el capítulo II («mientras la carta precedente corría a su destino por la línea de Francia») recoge el diálogo de dos contertulios que ocupan «dos lados opuestos de una mesa del mejor café de aquella ciudad costeña que se menciona en la carta» (Pereda, 1999: 461). En vano buscaremos su nombre en aquella misiva, donde tal «mención» se reduce a paráfrasis tan encomiásticas como discutibles ${ }^{16}$ : «la ciudad más importante de la costa española del mar Cantábrico... aquella ciudad, cuya playa no tiene semejante en España por su hermosura» (Pereda, 1999: 454 y

15. Cf. a este propósito de este edificio, y las demoliciones urbanas que tal denuncia propició, la nota de Simón Cabarga, en Pereda, 1977: 227-228.

16. No para Pereda, por supuesto: ya el narrador de Pedro Sánchez (1883) se refería a Santander como «el primer puerto del Cantábrico», corregido a partir de la segunda edición (1884) como «el mejor puerto de Cantábrico» (Pereda, 1992: 376). 
456). En efecto, según advertí antes, en Nubes de estío nunca se menciona la ciudad de Santander (salvo cuando, al final del libro, se fecha su redacción ${ }^{17}$ ). Mas no cabe duda de cuál es el referente urbano de la novela: una capital provinciana y costera que -sin duda- es transparente recreación de lo que era entonces uno de los centros preferidos para el veraneo elegante; ambiente que constituye el motivo fundamental de su argumento, según anuncia el título: el conflicto de unos amores veraniegos, que se resolverá -como las nubes de estío- en un chaparrón sin más graves consecuencias.

Se diría que el novelista, aunque no pretende escamotear el referente de su escenario ficticio, tampoco quiere evidenciarlo en exceso, pues sospecha que no todos sus conciudadanos aceptarán reconocerse en la burguesía provinciana satirizada en la historia. ${ }^{18}$ Pero uno de ellos, Marcelino Menéndez Pelayo (acaso por su irreprimible vocación erudita) quiso dejar constancia de tales semejanzas -más bien, identidades-y anotó cuidadosamente en los márgenes de su propio ejemplar de Nubes de estío (guardado ahora, con todos sus libros, en la Biblioteca que lleva su nombre) los lugares, las personas, las entidades, los asuntos de la vida local aludidos en la ficción ${ }^{19}$. Esas anotaciones nos permiten reconocer en aquellos dos contertulios del café a su hermano Enrique Menéndez Pelayo ${ }^{20}$ y al mismo autor de la novela, certeramente caricaturiza$\mathrm{do}^{21}$, que mantenían su tertulia en el Café Suizo, situado en lo que entonces se llamaba El Muelle y hoy es el Paseo de Pereda. Así describe el narrador el panorama que desde allí podía (y puede) contemplarse:

el ambiente salino que se respiraba desde allí, despertaba en los ojos nuevas y más fuertes ansias de contemplar el panorama grandioso que tenían delante en cuanto miraban hacia afuera, saltando por el estorbo de la abigarrada muchedumbre que hormigueaba en la empedernida faja que sirve de divisoria entre los edificios enfilados con el del café de que se trata, obras mezquinas de los hombres, y aquella incomparable marina, obra maravillosa de Dios. (Pereda, 1999: 462).

17. En «SANTANDER, diciembre de 1890» (Pereda, 1999: 797).

18. Como, por cierto, sucedió con un santanderino, que creyó ver la caricatura de un comerciante, pariente suyo y recientemente fallecido, en uno de los tipos locales, y a punto estuvo de llegar a las manos con el novelista en plena calle; lo comento en González Herrán, 1999: 435.

19. En mi edición (Pereda, 1999) he recogido y comentado esas anotaciones, añadiendo las noticias y referencias que otros investigadores y yo mismo hemos alcanzado a identificar.

20. Médico y colaborador en la prensa local, donde firmaba como Casa-Ajena: Casallena se llama el personaje de la novela.

21. «hombre que ya le doblaba la edad [en 1890 Pereda tenía 57 años y Enrique Menéndez 29] y con cara de pocos amigos [...] cara hosca [...] cara de coronel de reemplazo» (Pereda 1999:461-463). 
La tertulia (a la que se han ido incorporando otros personajes) concluye $-y$ con ello, también el capítulo- al final de la tarde: «ya comenzaban los sirvientes a encender los mecheros del café, señal de que también estarían encendiéndose las luminarias del ferial» (Pereda, 1999: 483). Un ferial, por cierto, que acaso sea el mismo aludido en el texto de Sotileza antes citado. Y es que, como antes apunté, el Santander de Nubes de estío es el anunciado en aquellos párrafos del capítulo I, pues ya tiene escolleras, ferrocarriles, tranvías urbanos, hoteles en el Sardinero, ferias y barracones en la Alameda segunda...; elementos todos ellos que, en buena parte, configuran el perfil urbano de esa ciudad innominada que es el escenario de esta novela. El ferrocarril -o más precisamente, la llegada del tren de Madrid-ocupa un notable episodio en el capítulo $\mathrm{VI}^{22}$; los tranvías y trenes urbanos que llevan a la zona de las playas, los hoteles y salones de conciertos que allí funcionan, en el capítulo IV, donde también se mencionan aquellas ferias y barracones ${ }^{23}$.

Pero si Sotileza precisaba los nombres de los lugares, instituciones y personas de la ciudad, que así podían ser fácilmente reconocibles para quienes fueron sus habitantes en ese tiempo, Nubes de estío los escamotea y disfraza (a veces de modo transparente ${ }^{24}$ ), pero no sus descripciones, tan precisas como identificables. Especial importancia tiene, a este propósito, el capítulo XII, cuyo elocuente título ( «De brujuleo») anuncia su carácter itinerante, como aquellos de Sotileza: en este el narrador acompaña a los personajes Casallena y Juanito Romero en su paseo por las calles más céntricas y comerciales de la capital, para luego tomar el ferrocarril urbano hasta los baños del Sardinero (aunque no se menciona tal nombre); el viaje permite al narrador demorarse primero «en la contemplación del hermoso panorama que iba descubriéndose

22. Véanse mis notas en Pereda, 1999: 535-538.

23. Véanse mis notas en Pereda, 1999: 513.

24. Los periódicos locales El Océano, que se corresponde con el santanderino El Atlántico, dirigido precisamente por Enrique Menéndez Pelayo, El Eco Mercantil, cuyo referente sería El Boletín de Comercio o La Bocina del País, que sería La Voz Montañesa; la Alianza Mercantil e Industrial, eco de la Liga de Contribuyentes; las calles comerciales de San Basilio y la Negra, que sin duda aluden a las de San Francisco y la Blanca; el paseo de El Mantón, que se correspondería con la Plaza del Pañuelo; Pedretas, mencionado como embarcadero en la bahía bien puede referirse a Pedreña; el Casino Recreativo, que don Marcelino identifica en su nota como el Círculo de Recreo; lo mismo con el río Pipas (=Río Cubas), la lancha la Pitorra (=la Corcornera), las hermanas Sotillo (=las Montero), Juan Fernández (=Pedro Sánchez, pseudónimo literario de José María Quintanilla), Fabio López (=Sinforoso Quintanilla), Sancho Vargas (=Antonio Dehesa), Juan Aceñas (=Molino), Juanito Romero (=Pepe Zumelzu), Pancho Vila (=Federico Vial), la clásica Perfumería (=la guantería de Juan Alonso), las Catacumbas (=la tertulia de Sinforoso Quintanilla en la calle Alta); Octavio (=Agabio). Identifico y comento todas esas alusiones en mis notas en Pereda, 1999: passim. 
a la derecha» $»^{25}$,y, al llegar a las playas, la descripción abarca también al paisaje humano que allí se ha instalado:
A los pocos instantes otro panorama distinto y más grandioso que el anterior, por su imponente sencillez: la mar sin límites, tranquila, llana a la vista, azul, diáfana como cielo sin nubes; a lo largo de la costa, y sobre las arenas de la playa, una línea hervorosa y blanca, recortando el azul brillante de las aguas; entre los pliegues de aquel festón del arenal, unos bultitos negros rebullén- dose... A uno de los tres señores de los hongos feos se le ocurrió la siguiente comparación: "parece un inmenso manto de crespones verdosos, ribeteado de armiños... con ratones, tendido al sol.» Casallena celebró la ocurrencia, porque le pareció exactísima hasta en lo de los ratones; sólo que le desen- cantó mucho el detalle, considerando que esos ratones de la imagen, vivos y efectivos, tal vez fueran lo más florido de las elegantes bellezas que tanto ad- miraba él. Y mira que mira hacia la playa, cuanto más miraba y contemplaba el cuadro, más exacta le parecía la comparación del personaje del hongo feo. «No hay que darle vueltas», concluyó diciendo para sí; «eso y no otra cosa es lo que parecen iratones!... pero en remojo, que es mucho peor todavía.» (Pereda, 1999:623-624).

Aunque sea uno de los personajes de la novela quien eso concluye, no cabe duda de que su reflexión expresa la opinión del autor, cuyo desdén y hostilidad hacia los veraneantes, sin dejar de ser muestra de su inveterada xenofobia, lo es también de su rechazo por la nueva sociedad que aquellos representan. De ahí los comentarios que formula el narrador en el último capítulo, cuando -resuelto ya el pequeño conflicto que sostuvo la trama argumental-el final del veraneo devuelve a la ciudad su fisonomía y ritmo tradicionales:

En la ciudad aconteció entonces algo parecido a lo que acontece en el seno de la patriarcal familia al siguiente día de despedir a los parientes y amigos que vinieron con motivo de las fiestas del santo patrono del lugar. Cada cual vuelve a su oficio, y a su ropa, y a su cuarto, y a su cama, y a su sitio en la mesa, y a su andar y vivir ordinarios, dentro y fuera de la casa: unos con pesadumbre por amor a la vida ruidosa y desordenada, y otros muy complacidos por gustar del método reglamentado, de la puchera clásica, del hogar en orden... y de una prudente y saludable economía; porque los regodeos y jolgorios, por breves que sean, siempre resultan caros.

La gente moza, con la espalda vuelta a las frías soledades de la playa y la vista fija en los pavorosos problemas del invierno que se les venía encima, se quedó suspirando y royéndose las uñas [...]

En cambio, los padres y otros ciudadanos que habían pasado ya de la edad de las ilusiones juveniles, se encontraban tan guapamente en aquella tranquilidad y en aquel orden beatíficos, como las personas cuerdas del ejemplo de más atrás, después de largarse sus huéspedes con el desorden y los

25. Véanse mis notas en Pereda, 1999: 622-623.

Anales, 24, 2012, pp. 111-124 
ruidos a otra parte. La ciencia del bien vivir no consiste, al fin y al cabo, en otra cosa que en conformarse cada cual con lo que tiene en su casa; y en ese particular, eran unos verdaderos sabios los hombres de aquella ciudad costeña, que no se entristecían cosa maldita en invierno con la falta de los huéspedes del verano. (Pereda, 1999: 785).

Representantes característicos de ese grupo social («ciudadanos que habían pasado ya de la edad de las ilusiones juveniles») son, en la novela, los contertulios del café Suizo que conocimos en el capítulo II, que en este final recuperan su habitual lugar de reunión en la casa de uno de ellos, que llaman «Las catacumbas» (título de este capítulo $\mathrm{XXV}^{26}$ ). De nuevo encontramos aquí al innominado personaje cuyo modelo sería el propio autor («hombre algo dado al vicio de las letras», se dice ahora de él) y que será quien cierre la novela, cuando concluida la tertulia, camina solitario hacia su domicilio, «admirándose, por casualidad, de lo que abundaba en el mundo la materia novelable, y deplorando amargamente al mismo tiempo que no le hubiera dotado Dios a él del arte necesario para saber utilizarla en la estrechez de los moldes de su ingenio» (Nubes, ed. cit. pp. 796-797).

Esas palabras finales de la novela constituyen una interesante reflexión de índole metanarrativa, según he explicado en otra ocasión («el propio autor, tras haber escuchado el relato de toda la historia por boca del narrador, ironiza sobre su propia capacidad de novelista» ${ }^{27}$ ), pero también nos permiten señalar otra curiosa similitud con la novela de 1885 , que se cerraba con un recurso similar, aunque menos sutil. En el capítulo XXIX («En qué paró todo ello») el narrador, tras excusarse por no describir detalladamente algo que el autor ya había contado en otra ocasión ${ }^{28}$, continúa con una expansión que reitera lo declarado en el prólogo-dedicatoria:

Y como no queda otro asunto por ventilar de los tocantes a este libro, dejémoslo aquí, lector pío y complaciente, que hora es ya de que lo dejemos; mas no sin declararte que, al dar reposo a mi cansada mano, siento en el corazón la pesadumbre que engendra un fundadísimo recelo de que no estuviera guardada para mí la descomunal empresa de cantar, en medio de estas generaciones descreídas e incoloras, las nobles virtudes, el mísero vivir, las grandes flaquezas, la fe incorruptible y los épicos trabajos del valeroso y pintoresco mareante santanderino. (Pereda, 1996: 401).

26. Y que la anotación marginal de don Marcelino identifica como «La tertulia de Sinforoso Quintanilla [uno de los amigos más próximos de Pereda] en la Calle Alta».

27. González Herrán, 1977: 380; lo cito también en la nota final de mi edición (Pereda, 1999: 797).

28. Cf. lo dicho en la nota 5, a propósito de «La leva». 
Por supuesto que en ambos finales el artificio retórico es el mismo: si en el de Sotileza recelaba de su capacidad para recrear la vida del pescador santanderino (así expresamente mencionado), en el de Nubes pondrá en duda su ingenio para saber aprovechar la materia novelable tan abundante «en el mundo» (que es aquí el de la sociedad veraneante). Mas los lectores para quienes preferentemente había escrito ambas novelas (así lo declarase o no), sus paisanos y coetáneos, coincidieron en apreciar en ellas lo muy acertadamente que había sabido recrear la ciudad de Santander en momentos y aspectos muy diferentes de su historia reciente.

\section{BIBLIOGRAFÍA}

AlAS, Leopoldo, La Regenta, edición e introducción de José María Martínez Cachero, Oviedo, Ediciones Nobel, 1994.

BONET, Laureano, «Introducción biográfica y crítica» a su edición de José María de Pereda, La puchera, Madrid, Castalia, 1980, pp. 7-63.

GonzÁlez Herrán, José Manuel, «La técnica narrativa de José María de Pereda: Nubes de estío, novela de perspectivas», BBMP, LIII (1977), pp. 357-381.

GonZÁlez Herrán, José Manuel, «José María de Pereda: entre el costumbrismo y la novela regional», en Víctor García de la Concha (dir.), Historia de la Literatura Española. 9, L. Romero Tobar (coord.), Siglo XIX (II), Madrid, EspasaCalpe, 1998, pp. 436-456.

GonzÁlez Herrán, José Manuel, «Introducción»a José María de Pereda, Nubes de estío, en Obras Completas, VII, Santander, Ediciones Tantín, 1999, pp. 429-442.

GONZÁLEZ HERRÁN, José Manuel, «La novela santanderina», en «1906-2006: José María de Pereda», Suplemento de El Diario Montañés (Santander), miércoles 1 de marzo de 2006, p. 51.

GONZÁlez Herrán, José Manuel, «Los lugares de la ficción y sus nombres, en la novela realista española del siglo XIX. (Un ejemplo de Palacio Valdés, con alusiones a Pereda, Pardo Bazán, Alas)», en António Apolinário Lourenço e Oswaldo Manuel Silvestre, eds., Literatura, Espaço, Cartografias, Coimbra, Centro de Literatura Portuguesa da Universidade de Coimbra, 2011, pp. 157-176.

Gullón, Ricardo, Vida de Pereda, Madrid, Editora Nacional, 1944.

Montesinos. José F., Pereda o la novela idilio, Berkeley-Los Angeles-México, University of California Press-El Colegio de México, 1961; segunda edición, aumentada, Madrid, Castalia, 1969.

PARDo BAZÁn, Emilia, La Tribuna, introducción y notas de Benito Varela Jacome, Madrid, Cátedra, 1975. 
Pereda, José María, Sotileza, edición, notas y apéndice por José Simón Cabarga, Santander, Institución Cultural de Cantabria, 1977.

Pereda, José María, Pedro Sánchez, edición de José Manuel González Herrán, introducción y notas de Francisco Pérez Gutiérrez, en Obras Completas, V, Santander, Ediciones Tantín, 1992.

Pereda, José María, Sotileza, edición de Anthony H. Clarke, introdución y notas de Francisco Caudet, en Obras Completas, VI, Santander, Ediciones Tantín, 1996.

Pereda, José María, Nubes de estío, edición, introducción y notas de José Manuel González Herrán, en Obras Completas, VII, Santander, Ediciones Tantín, 1999.

Villanueva, Darío, Teorías del realismo literario, Madrid, Instituto de EspañaEspasa Calpe, 1992; cito por la segunda edición, corregida y aumentada: Madrid, Biblioteca Nueva, 2004.

Fecha de recepción: 25-1-2011

Fecha de aceptación: 30-3-2012 